\title{
Ge-free chalcogenide glasses based on GaSbSe and their stabilization by iodine incorporation
}

\author{
Alicia LeComte ${ }^{1}$, Virginie NAZABaL ${ }^{1}$, DAVId Le COQ $^{1}$ AND LAURent CalveZ ${ }^{1}$, \\ ${ }^{1}$ Equipe Verres et Céramiques, UMR-CNRS 6226 Institut des Sciences Chimiques de Rennes, \\ Université de Rennes 1, 263 Avenue Général Leclerc, Rennes, 35042, France \\ *laurent.calvez@univ-rennes1.fr +33-2 23236713
}

\begin{abstract}
In this paper, we report the existence of new bulk chalcogenide glasses free of germanium and transparent up to $18 \mu \mathrm{m}$. The investigation of the Ga-Sb-Se ternary diagram has allowed bringing out the presence of a small glassy domain mainly formed for compositions with low contents of Ga. Thermal, optical and mechanical characteristics of these glasses have been studied. In order to enhance the low stability against crystallization pure iodine was successfully added. At last, structural analysis by Raman spectroscopy was performed to point out the iodine addition effect.
\end{abstract}

(c) 2017

Keywords: Chalcogenide glass; Glassy domain; Optical materials; Thermal analysis; Optical properties

\section{Introduction}

The civilian and defense applications of transparent chalcogenide glasses are mainly devoted to night vision because of their large window of transparency recovering the second $(3-5 \mu \mathrm{m})$ and third (8$14 \mu \mathrm{m})$ atmospheric window [1].

For now, most of the marketable chalcogenide glasses used for night vision applications are made of germanium and selenium combined with gallium or antimony. Germanium is from far the most expensive compounds constituting these glasses. Some other glasses based on $\mathrm{As}_{2} \mathrm{Se}_{3}$ are also available but they suffer from their high photosensibility, crystallizing or strongly ageing under light. It is then of a paramount interest to develop new glass compositions free of germanium to give a better competitiveness toward monocrystalline germanium or polycrystalline $\mathrm{ZnSe}$.

In this paper, new bulk glasses belonging to the Ga-Sb-Se binary system are described. In fact, the possibility to obtain nano-amorphous domain was demonstrated on several glass compositions by using ultrafast laser heating and quenching for making phase change memory materials [2]. However, never bulk glasses belonging to this domain were synthesized by the conventional melt-quenching method in silica tubes.

More recently, Jiao et al [3,4] worked on the analogous sulfide system showing a good ability to form glass with gallium and antimony entities. The substitution of sulfur by selenium is known to strongly broaden the transmission window in the infrared range permitting to take the full benefit of the third atmospheric window ranging from 8 to $14 \mu \mathrm{m}$.

\section{Experimental}

Glasses in the Ga-Sb-Se system were synthesized by melting the constituent elements $(\mathrm{Ga}, \mathrm{Sb}, \mathrm{Se}$ of $99.999 \%$ ) under vacuum in a sealed silica tube of $8 \mathrm{~mm}$ and $10 \mathrm{~mm}$ as inner and outer diameter, respectively. The ampoule was heated up in a rocking furnace at $950^{\circ} \mathrm{C}$ for 12 hours and then the temperature was reduced to $870^{\circ} \mathrm{C}$ for 2 hours before being quenched in iced water. The sample was annealed $10^{\circ} \mathrm{C}$ below Tg for 5 hours to minimize the inner stresses induced by the water quenching. The glass was finally slowly cooled down to room temperature. Special cares were taken for the iodine-based sample syntheses using pure iodine $(5 \mathrm{~N})$ as starting element because of its high vapor tension under vacuum. The procedure described by Zhu et al has been carefully reproduced by maintaining the silicon tube in liquid nitrogen during pumping under vacuum [5]. 
The amorphous or crystalline state of synthesized Ga-Sb-Se samples allowing delimiting the glass-forming domain in this system has been determined using X-Ray Diffraction analysis on ground samples. These experiments were carried out at room temperature with a Phillips PW3710 diffractometer equipped with a copper anode $(\lambda=1.5406 \AA)$. The scattering intensities were measured over an angular range of $10^{\circ} \leq 2 \theta \leq 80^{\circ}$ with a step-size of $\Delta(2 \theta)=0.02^{\circ}$ and a count time of $2 \mathrm{~s} / \mathrm{step}$.

The transmission measurements were performed with a double beam CARY spectrometer in the visible to calculate the optical band-gap. By convention, the optical band-gap has been calculated and obtained at $10 \mathrm{~cm}^{-1}$.according to the Beer-Lambert law.

The infrared transparency has been checked using a Bomem Fourier transform infrared spectrometer from 2 to $25 \mu \mathrm{m}$.

Scanning Electronic Microscope (SEM, JEOL IT 300) coupled with Energy Dispersive Spectrometer was used to analyze the glass composition and to verify the good accordance between the theoretical and experimental compositions especially when volatile iodine was incorporated.

Differential Scanning Calorimetry experiments (DSC 2010 TA Q20) were performed to measure the glass transition temperature ( $\mathrm{Tg}$ ) and the crystallization temperature $(\mathrm{Tx})$, corresponding to the onset points. The experiments were led from room temperature up to $400^{\circ} \mathrm{C}$ using a heating rate of $10^{\circ} \mathrm{C} / \mathrm{min}$.

Hardness and toughness were determined using a Vickers micro indenter MATZUZAWA, with a charge of $50 \mathrm{~g}$ for $5 \mathrm{~s}$. The reported value is an average of ten measurements.

Raman acquisitions were made with the HR800-785nm optical density D2 with a laser wavelength at $785 \mathrm{~nm}$.

The thermal expansion coefficient $(\alpha)$ was determined by the means of a TMA 2840CE TA Instrument at $0.2 \mathrm{~N}$ from $20^{\circ} \mathrm{C}$ up to $120^{\circ} \mathrm{C}$ with a ramp of $2^{\circ} \mathrm{C} / \mathrm{min}$.

The glass density was measured using the classical Archimedes technique in distilled water. The obtained value for each composition is an average of five measurements.

\section{Results and discussion}

\subsection{Glass forming domain}

The boundary of glassy domains directly linked to the small frontier between a glass and a glassceramic slightly crystallized is often still subject to discussion. In this study, only samples presenting both a high transparency in the infrared range and no crystallization signature in XRD patterns have been considered as glasses. In other words, samples presenting scatterings in the near IR but fully transparent in the mid-IR, constitute the boarder of the glassy domain, even if no crystalline signature is observed by XRD (crystals proportions <5\%). The Figure 1 shows the vitreous domain in the Ga$\mathrm{Sb}$-Se system obtained by taking into account the previous considerations. It can be noticed that the Ga content ranges from 4 to $12 \%$ at. Moreover, the minimum rate of Se is $50 \%$ at. and no glass composition is found if this rate is higher than $62.5 \%$ at. Next, the minimum and the maximum of $\mathrm{Sb}$ content are 20 at. $\%$ and 40 at. \% respectively. Finally, the glass domain is mainly elongated according to the Se axis and poorly spread out. For a better reading, the series of samples has been named as "GSS-X". 


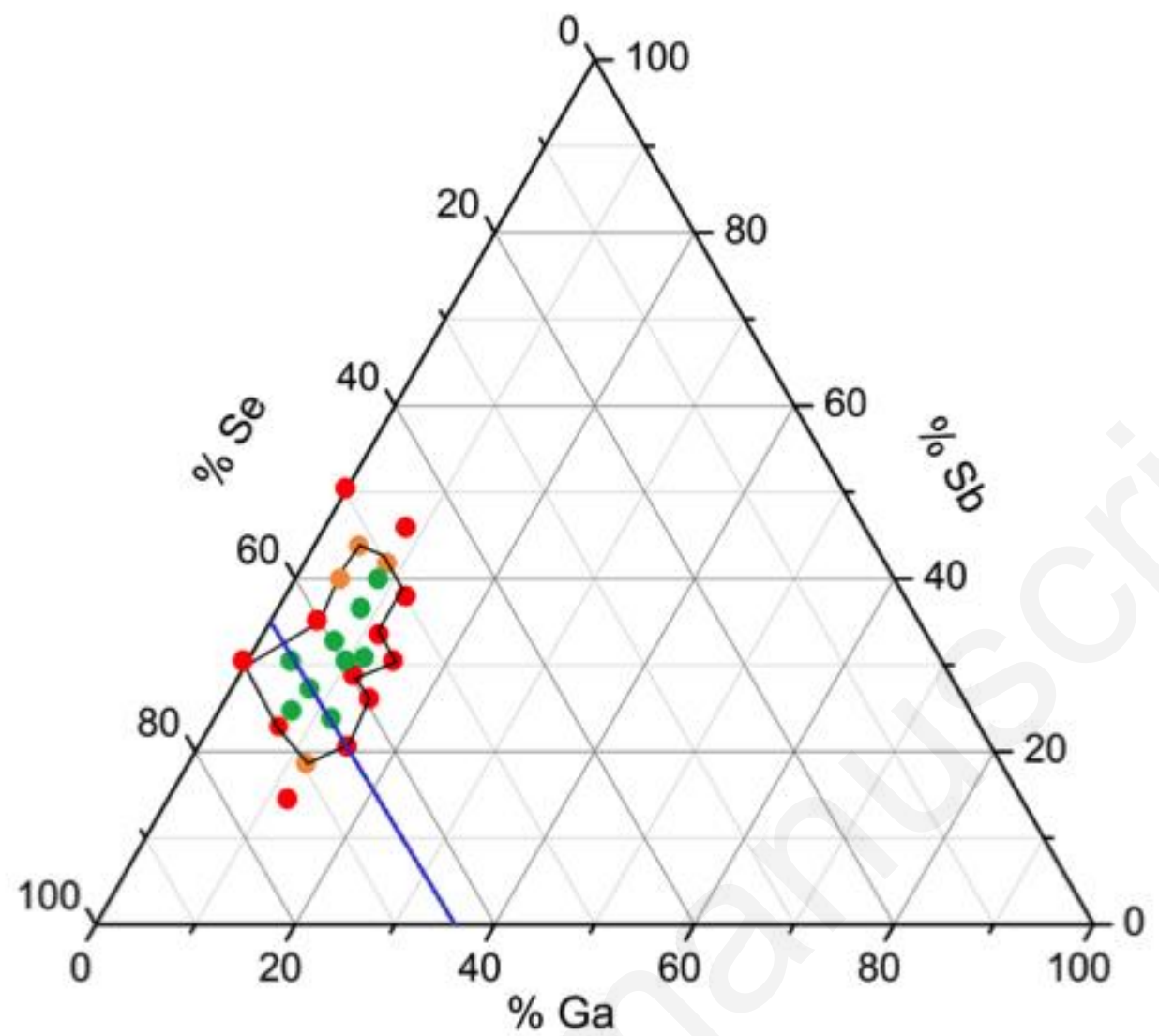

Fig. 1. Ga-Sb-Se ternary diagram obtained by melt-quenching in sealed silica tubes. Red dots are crystallized, orange are glass-ceramics, and green dots are glasses.

\subsection{Thermo-mechanical properties}

Table 1. Thermal properties including $\mathrm{Tg}, \mathrm{Tx}$ and $\Delta \mathrm{T}=\mathrm{Tx}-\mathrm{Tg}\left(\mathrm{T} \pm 2^{\circ} \mathrm{C}\right)$ for glass samples belonging to the ternary system $\mathrm{Ga}-\mathrm{Sb}-\mathrm{Se}$

\begin{tabular}{lllll}
\hline & & $\mathrm{Tg}$ & $\mathrm{Tx}$ & $\Delta \mathrm{T}$ \\
\cline { 2 - 5 } Composition & Name & ${ }^{\circ} \mathrm{C}$ & ${ }^{\circ} \mathrm{C}$ & ${ }^{\circ} \mathrm{C}$ \\
\hline $\mathrm{Ga}_{4} \mathrm{Sb}_{31} \mathrm{Se}_{65}$ & GSS-1 & 168 & 216 & 48 \\
$\mathrm{Ga}_{8} \mathrm{Sb}_{24} \mathrm{Se}_{68}$ & GSS-2 & 180 & 233 & 53 \\
$\mathrm{Ga}_{8} \mathrm{Sb}_{27} \mathrm{Se}_{65}$ & GSS-3 & 175 & 252 & 77 \\
$\mathrm{Ga}_{8} \mathrm{Sb}_{32} \mathrm{Se}_{60}$ & GSS-4 & 227 & 292 & 65 \\
$\mathrm{Ga}_{8} \mathrm{Sb}_{37} \mathrm{Se}_{55}$ & GSS-5 & 212 & 305 & 93 \\
$\mathrm{Ga}_{8} \mathrm{Sb}_{40} \mathrm{Se}_{52}$ & GSS-6 & 211 & 293 & 82 \\
$\mathrm{Ga}_{10} \mathrm{Sb}_{30} \mathrm{Se}_{60}$ & GSS-7 & 236 & 304 & 68 \\
$\mathrm{Ga}_{12} \mathrm{Sb}_{23} \mathrm{Se}_{65}$ & GSS-8 & 180 & 257 & 77 \\
$\mathrm{Ga}_{12} \mathrm{Sb}_{31} \mathrm{Se}_{57}$ & GSS-9 & 230 & 300 & 70 \\
\hline
\end{tabular}

Glass stability against crystallization has been calculated according to $\Delta \mathrm{T}$, which corresponds to the difference between the onset crystallization temperature (Tx) and the glass transition temperature $(\mathrm{Tg})$. All the as-made glasses have $\Delta \mathrm{T}$ below than $100^{\circ} \mathrm{C}$, which indicates a low stability against crystallization. This parameter is of paramount importance in order to make IR optics by molding at higher temperature than $\mathrm{Tg}$, usually $\mathrm{Tg}+50^{\circ} \mathrm{C}$ for shaping lenses and $\mathrm{Tg}+100^{\circ} \mathrm{C}$ for drawing fibers. 
Moreover, glass transition temperatures are rather low compared to $\mathrm{Ge}-\mathrm{Sb}-\mathrm{Se}$ glasses (about $250^{\circ} \mathrm{C}$ ) and $\mathrm{Ge}-\mathrm{Ga}-\mathrm{Se}$ glasses (about $350^{\circ} \mathrm{C}$ ) $[6,7,8]$, showing a low reticulation of the glassy network. Although it can be assumed that $\mathrm{Se}$ and $\mathrm{Sb}$ are respectively two-fold and three-fold coordinated, the coordination of Ga can remain unclear [9]. In fact, many studies have [4,6,7,9,15] demonstrated that high concentration of Selenium elicits Se-Se chains according to the composition giving a higher flexibility to the network. The higher coordination number of $\mathrm{Ga}$ and $\mathrm{Sb}$ (respectively tetrahedral and pyramidal coordination for $\mathrm{Ga}$ and $\mathrm{Sb}$ with $\mathrm{Se}$ ) in vitreous system induces a breaking of the $\mathrm{Se}-\mathrm{Se}$ chains and consequently a higher reticulation of the glass network. It leads to a more rigid network with higher thermo-mechanical properties.

In the present study, the substitution of Se by $\mathrm{Ga}$ is characterized by an increase of $\mathrm{Tg}$ (see for ex : GSS- 1 and GSS- $9,185^{\circ} \mathrm{C}$ vs $230^{\circ} \mathrm{C}$, respectively) whilst the substitution of $\mathrm{Sb}$ by Ga tends to slightly decrease $\mathrm{Tg}$ ( See for ex : GSS- 1 and GSS- $8,185^{\circ} \mathrm{C}$ vs $180^{\circ} \mathrm{C}$ ). If we consider that the total coordination number is the main responsible of the Tg evolution, the first case can be easily explained. Unexpectedly, in the second case, the explanation based on a tetrahedral coordination of the Ga should also give higher $\mathrm{Tg}$ when $\mathrm{Sb}$ is substituted by Ga. Nevertheless, another $\mathrm{Tg}$ comparison between $\mathrm{Ga}_{10} \mathrm{Sb}_{30} \mathrm{Se}_{60}\left(\mathrm{Tg}=230^{\circ} \mathrm{C}\right)$ and $\mathrm{Ge}_{10} \mathrm{Sb}_{30} \mathrm{Se}_{60}\left(\mathrm{Tg}=277^{\circ} \mathrm{C}\right)$ [10], one can assume that the coordination number of Ga could be 3 rather than 4 since the germanium coordinate number is well-known to be 4 , and the glass based on Ge exhibits a higher $\mathrm{Tg}$.

Then, studies have been focused on glasses containing $65 \%$ at. of Se (blue line in Figure 1). The results of thermal and mechanical properties are listed in the table 2.

Table 2. Glass transition temperatures $(\mathrm{Tg}), \Delta \mathrm{T}$, density $(\rho)$, Vickers hardness $(\mathrm{Hv})$, thermal expansion coefficient $(\alpha)$ and optical band gap (Eg) calculated at $10 \mathrm{~cm}^{-1}$ of Ga-Sb-Se glasses

\begin{tabular}{lllllll}
\hline \multirow{3}{*}{ Name } & $\mathrm{Tg}$ & $\Delta \mathrm{T}$ & $\rho$ & $\mathrm{Hv}$ & $\alpha$ & $\mathrm{Eg}$ \\
\cline { 2 - 7 } & ${ }^{\circ} \mathrm{C}$ & & $\mathrm{g} \cdot \mathrm{cm}^{-3}$ & $\mathrm{Kg} \cdot \mathrm{mm}^{-2}$ & $\mu \mathrm{m} \cdot \mathrm{m}^{-1} \cdot{ }^{\circ} \mathrm{C}$ & $\mathrm{nm}$ \\
& $\pm 2{ }^{\circ} \mathrm{C}$ & & $\pm 0.2 \%$ & $\pm 1 \%$ & $\pm 10 \%$ & $\pm 2 \%$ \\
\hline GSS-1 & 168 & 48 & 5.030 & 131 & 23 & 1098 \\
GSS-3 & 175 & 77 & 5.212 & 158 & 16 & 970 \\
GSS-8 & 180 & 77 & 5.139 & 147 & 12 & 953 \\
\hline
\end{tabular}

From this low reticulation of the glass network follows rather low Vickers hardness ranging from 130 to $158 \mathrm{Hv}$ and a large range of relatively high thermal expansion extending from 12 to $23 \mu \mathrm{m} . \mathrm{m}^{-}$ ${ }^{1} .{ }^{\circ} \mathrm{C}$. As already demonstrated by Calvez et al. in the Ge-Ga-Se system, increasing amount of Gallium leads to a glass bleaching whatever the $\mathrm{Sb} / \mathrm{Se}$ ratio [8].

\subsection{Analysis of optical performance}

The infrared transmission curves of Ga-Sb-Se glasses are presented in figure 2. All the obtained glasses are black presenting a strong metallic reflection. The window of transparency ranges from about 1 to $18 \mu \mathrm{m}$ with a slight transparency up to $24 \mu \mathrm{m}$. The main point to highlight is the enlarged transmittance in the mid-IR compared to conventional Se-based glasses, which presents a cut-off at 16 $\mu \mathrm{m}$ instead of $18 \mu \mathrm{m}$ for Ga-Sb-Se glasses.

Even if no purification steps of raw materials were performed, the obtained glasses present a smooth transmission curve with very small $\mathrm{H}_{2} \mathrm{O}$ absorption bands. Several small absorption bands are located at 2.6, 3.1, 4.3, 6.3, 9.8, and $15.6 \mu \mathrm{m}$ due to $\mathrm{O}-\mathrm{H}, \mathrm{Ga}-\mathrm{H}, \mathrm{Se}-\mathrm{H}, \mathrm{H}_{2} \mathrm{O}, \mathrm{Si}-\mathrm{O}$ and Se-Se vibrations respectively [10]. It is important to point out the fact that contrarily to Ge-based glasses, no subsidiary purification is needed to obtain a flat transmittance in the 8-14 $\mu \mathrm{m}$ region corresponding to the optical window used for thermal imaging applications. 


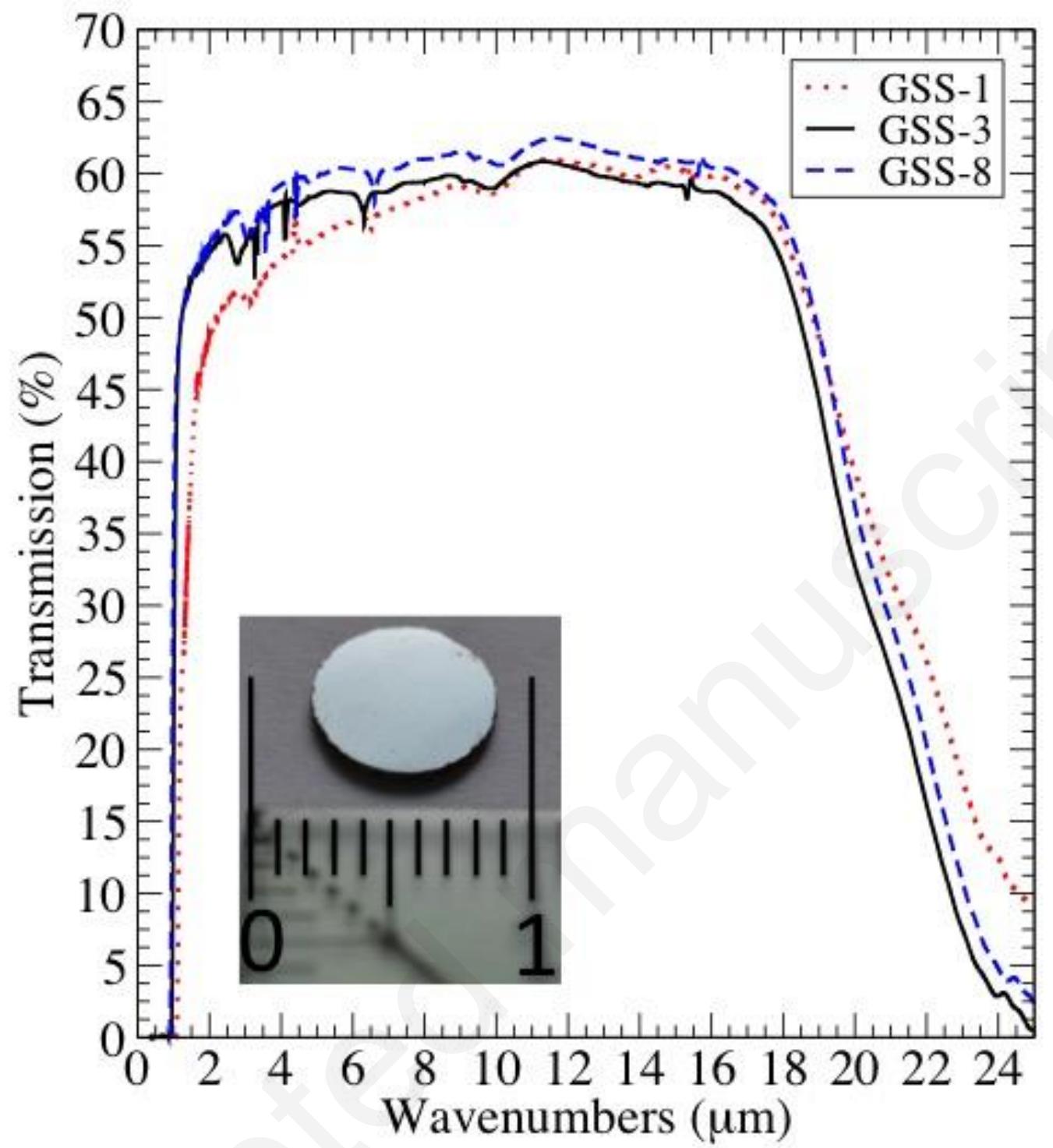

Fig. 2. Transmission curves of

Ga-Sb-Se glasses sets with $65 \%$ at. of Se (thickness: $1.7 \mathrm{~mm}$ )

\subsection{Enhancement of Ga-Sb-Se glasses thermal stability}

Considering the low thermal stability of the Ga-Sb-Se glasses, iodine has been incorporated in various amounts within the $\mathrm{Ga}_{8} \mathrm{Sb}_{27} \mathrm{Se}_{65}$ glass composition. In fact, it has already been demonstrated that iodine can be efficient to increase the glass stability of arsenic based glasses [11] as well as gallium based glasses [4,12]. Consequently, 2, 5, 10, 15 and $20 \%$ at. of pure iodine were introduced in the base glass by substitution of all atoms, using GSS3 $3_{100-\mathrm{x}} \mathrm{I}_{\mathrm{x}}$ formula, with $\mathrm{x}$ the atomic percentage of iodine.

As already mentioned, severe precautions have to be taken when manipulating iodine because of its high volatility and because it is a highly corrosive agent of metal, which could deteriorate rotor of vacuum pumps.

Due to the high volatility of iodine under vacuum, EDS experiments were performed to ensure the final iodine content. The final composition presents a very good accordance with the theoretical ones. Since the sample containing 20 at. \% of iodine is crystallized, the limiting content of iodine, which can be incorporated in this specific composition is 15 at. \%. Although this last composition is mainly 
amorphous some crystalline particles containing iodine are present yet. Thermo-mechanical properties of the obtained glasses are given in table 3 .

Table 3. Glass compositions, characteristics temperatures (Tg, Tx), $\Delta \mathrm{T}$, density ( $\rho$ ), Vickers hardness (Hv) and optical band gap (Eg) calculated at $10 \mathrm{~cm}^{-1}$ of $\mathrm{GSS} 3_{100-\mathrm{x}} \mathrm{I}_{\mathrm{x}}$ samples.

\begin{tabular}{|c|c|c|c|c|c|c|c|}
\hline & & $\mathrm{Tg}$ & Tx & $\Delta \mathrm{T}$ & $\rho$ & $\mathrm{Hv}$ & $\mathrm{Eg}$ \\
\hline Composition & Name & $\begin{array}{l}{ }^{\circ} \mathrm{C} \\
\pm 2^{\circ} \mathrm{C}\end{array}$ & $\begin{array}{l}{ }^{\circ} \mathrm{C} \\
\pm 2^{\circ} \mathrm{C}\end{array}$ & $\pm 0.2 \%$ & $\begin{array}{l}\text { g.cm }{ }^{-3} \\
20^{\circ} \mathrm{C} \\
+1 \%\end{array}$ & $\begin{array}{l}\text { Kg.mm }{ }^{-2} \\
\pm 10 \%\end{array}$ & $\begin{array}{l}\mathrm{nm} \\
\pm 2 \%\end{array}$ \\
\hline $\mathrm{Ga}_{8} \mathrm{Sb}_{27} \mathrm{Se}_{65} \mathrm{I}_{0}$ & ${ }_{100} \mathrm{GSS} 3{ }_{0} \mathrm{I}$ & 175 & 252 & 77 & 5.212 & 159 & 970 \\
\hline $\mathrm{Ga}_{7.8} \mathrm{Sb}_{26.5} \mathrm{Se}_{63.7} \mathrm{I}_{2}$ & ${ }_{98} \mathrm{GSS} 3{ }_{2} \mathrm{I}$ & 170 & 247 & 77 & 5.097 & 161 & 954 \\
\hline $\mathrm{Ga}_{7.6} \mathrm{Sb}_{25.6} \mathrm{Se}_{61.8 \mathrm{I}} \mathrm{I}_{5}$ & ${ }_{95} \mathrm{GSS} 3{ }_{5} \mathrm{I}$ & 157 & 245 & 92 & 5.016 & 143 & 928 \\
\hline $\mathrm{Ga}_{7.2} \mathrm{Sb}_{24.3 .3} \mathrm{Se}_{58.5} \mathrm{I}_{10}$ & ${ }_{90} \mathrm{GSS}-3{ }_{10} \mathrm{I}$ & 125 & 200 & 75 & 4.971 & 124 & 906 \\
\hline $\mathrm{Ga}_{6.8} \mathrm{Sb}_{22.9} \mathrm{Se}_{55.3} \mathrm{I}_{15}$ & ${ }_{85} \mathrm{GSS}-3{ }_{15} \mathrm{I}$ & 105 & 135 & 30 & 4.875 & 116 & 872 \\
\hline
\end{tabular}

Iodine incorporation leads to a strong decrease of $\mathrm{Tg}$ from $175^{\circ} \mathrm{C}$ down to $105^{\circ} \mathrm{C}$ for compositions ranging from 0 to $15 \%$ at., respectively. The glass reticulation network progressively collapses by forming non-bridging iodine at the end of chains [8]. In parallel, higher flexibility stabilizes the vitreous network when adding $5 \%$ at. of iodine, reaching a $\Delta \mathrm{T}$ close to $100^{\circ} \mathrm{C}$ [13]. Overpassing this rate leads to a decrease of the thermal stability by favoring phase separation within the glassy matrix and hence the crystallization of phases like $\mathrm{Ga}_{2} \mathrm{Se}_{3}$ or $\mathrm{Sb}_{2} \mathrm{Se}_{3}$. The lowering of $\mathrm{Tg}$ can be an important drawback in the idea to prepare IR lenses since anti-reflective or hardener coatings are deposited at about $150^{\circ} \mathrm{C}$ and thus could deform the glass. Moreover, even if $\Delta \mathrm{T}$ is increased favoring its shaping by molding, the decreasing of reticulation network leads to a decrease of hardness. 


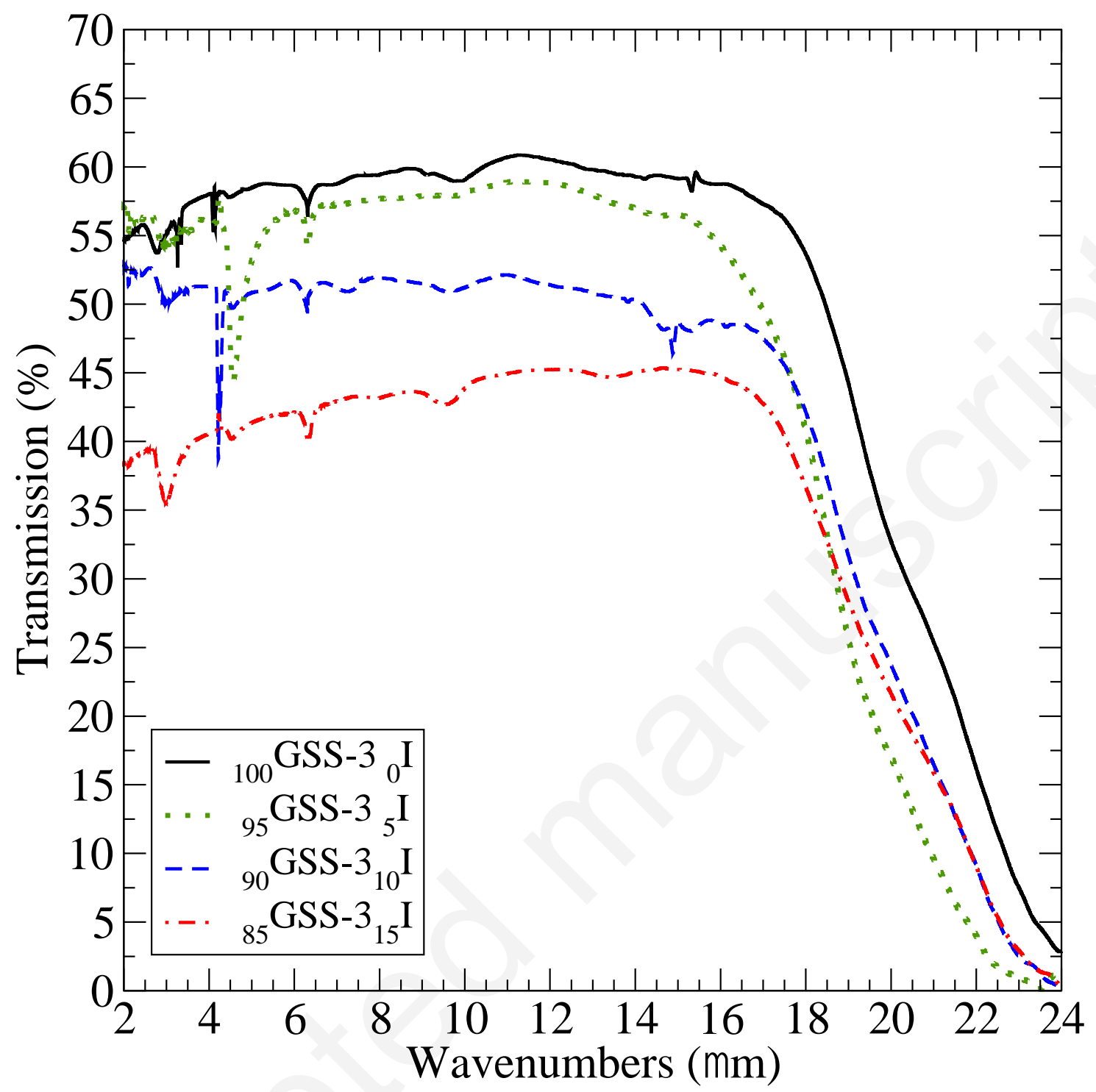

Fig. 3. Transmission curves of the different ${ }_{100-x}$ GGS3 ${ }_{x}$ I glasses (thickness: $1.7 \mathrm{~mm}$ ), with $x$ the atomic percentage of iodine ranging from 0 to 15 .

Transmission curves presenting the influence of iodine incorporation on the maximum of transmittance are showed in figure 3. As expected, glasses show increased $\mathrm{O}-\mathrm{H}$ and $\mathrm{H}_{2} \mathrm{O}$ absorption bands at 2.6 and $6.3 \mu \mathrm{m}$ due to increasing amount of hygroscopic iodine. However, on the contrary to Zhu et al. [5] who demonstrated an improved transmittance when adding iodine, one can observe a slight decrease of the maximum of transmittance. Even if a lower transmittance could be expected due to the addition of highly polarizable iodine, which should increase the refractive index, the decreases of transmittance in our case are too important to be explained only by this fact. One can assume that even if our samples are mainly amorphous, very few big crystalline particles can induce Mie scatterings inducing a slight decrease of the maximum of transmittance.

Moreover, without considering the changes in the maximum of transmittance, the transmission cut-off remains almost unchanged at $18 \mu \mathrm{m}$ whatever the iodine content. 


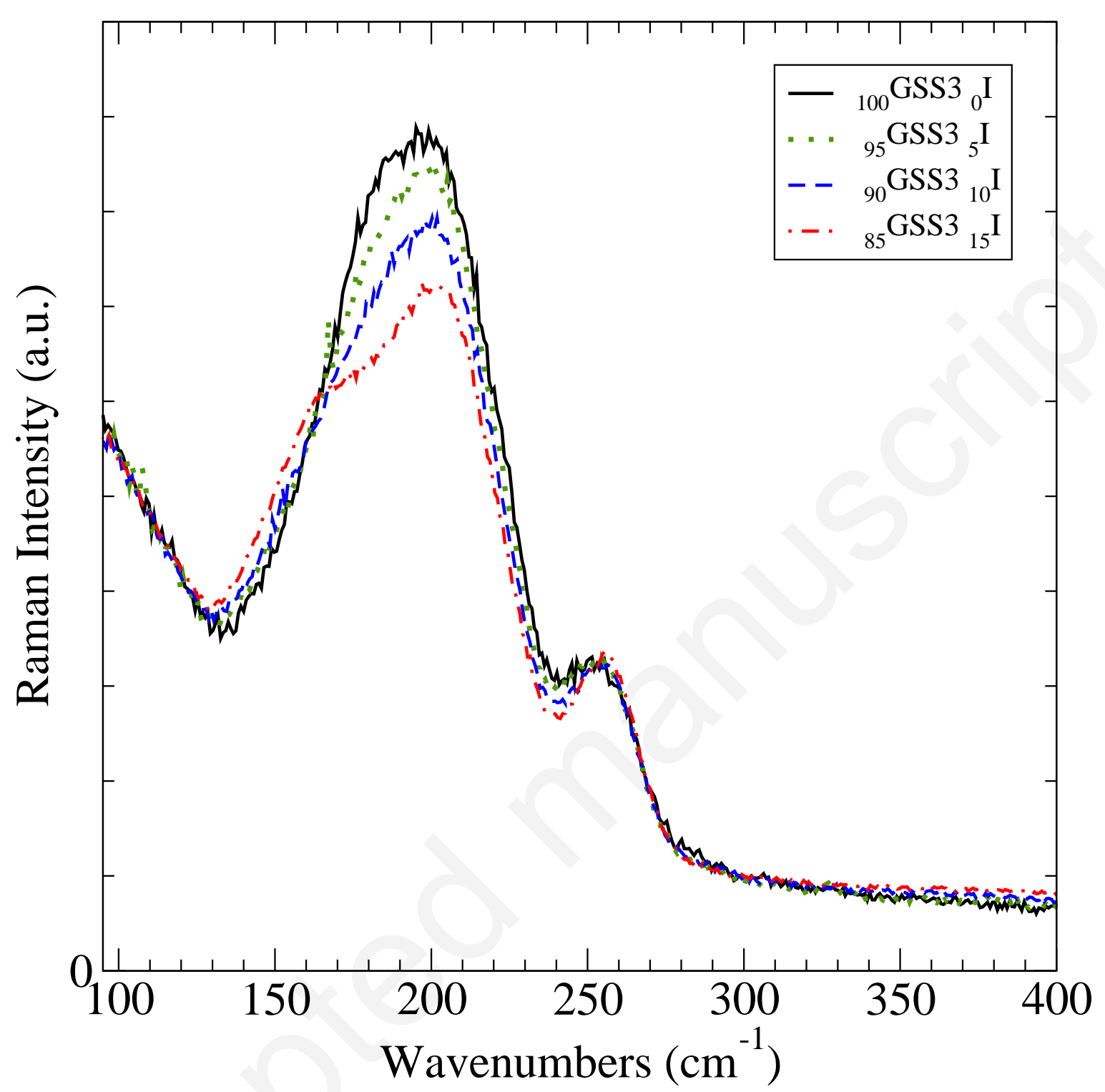

Fig. 4. Raman spectroscopy of the ${ }_{100-x} \mathrm{GGS} 3{ }_{x} \mathrm{I}$ glasses (with $\mathrm{x}=5 \%$ at of Iodine in green, 10 in blue and 15 in red)

The most stable vitreous compound in the sets at $65 \%$ at. of Se is over-stoichiometric, presenting an excess of Se considering standard two-fold coordination for Se, three-fold for $\mathrm{Sb}$ and the four-fold for coordinates for $\mathrm{Ga}$ as usually proposed in literature [14]. The vibrational band centered around $184 \mathrm{~cm}^{-}$ 1 indicates the presence of pyramidal $\left[\mathrm{SbSe}_{3 / 2}\right.$ ] [15-18] entities otherwise $200 \mathrm{~cm}^{-1}$ can represent [GaSe $4 / 2]$ tetrahedral $[14,18,19]$. The excess of Se appears at $235 \mathrm{~cm}^{-1}$ and $265 \mathrm{~cm}^{-1}$ corresponding to short homopolar Se-Se chains (from 2 to 4 repetitions) and long ( $\mathrm{Se}_{8}$ rings) chains respectively [1820]. In case of chemical disorder or Se deficit, the presence of homopolar bonds can be expected like $\mathrm{Ga}-\mathrm{Ga}$, probably around $180 \mathrm{~cm}^{-1}$, considering the Ge-Ge vibrations at $170 \mathrm{~cm}^{-1}[22,23]$ and $\mathrm{Sb}-\mathrm{Sb}$ vibrations at $150 \mathrm{~cm}^{-1}[24,25,26]$.

The impact of iodine on the glass structure has been investigated by Raman spectroscopy (figure 4). Iodine is a compound of large size and mass, with bond strength greater than other atoms of the system. Added to the glass, a shift of the vibrational peaks towards shorter wavenumber is expected in Raman measurement. First hypothesis consists in assuming the creation of new entities from $\mathrm{GaSe}_{4}$ 
$[14,18,19]$ and $\mathrm{SbSe}_{3}[15-18]$ entities with substitutions of iodine like $\mathrm{GaSe}_{4-\mathrm{x}} \mathrm{I}_{\mathrm{x}}(\mathrm{x}=0$ to 3$)$ or $\mathrm{SbSe}_{3 \mathrm{x}} \mathrm{I}_{\mathrm{x}}$ ( $\mathrm{x}=0$ to 3 ). In contrast, atoms can change their coordination with the addition of iodine with, for instance, formation of $\mathrm{GaI}_{3}$ or $\mathrm{Ga}_{2} \mathrm{I}_{6}$ [19]. Moreover, the peaks corresponding to the homopolar Se-Se bonds [18-20] are also modified. In fact, it is possible to estimate a de-crosslinking of the long Se chains by terminal iodine atoms leading to a less distributed distribution of vibration and therefore better defined peaks around $235 \mathrm{~cm}^{-1}$. Even if Ga-Ga bonds are not clearly identified, the possibility to incorporate iodine within ethane like $\mathrm{GaSe}_{3}-\mathrm{GaSe}_{3}$ units leading to a growing peak around $180 \mathrm{~cm}^{-1}$ cannot be excluded [3].

From a structural point of view, the ability to form glasses by associating the non glass-forming atoms $\mathrm{Ga}$ and $\mathrm{Sb}$ will be the starting point of a fundamental research that will be carried out combining MAS NMR of ${ }^{71} \mathrm{Ga}$ and ${ }^{77} \mathrm{Se}$, neutron diffraction and DFT glass forming simulation.

\section{Conclusion}

Even if not expected considering the high tendency of $\mathrm{Ga}$ and/or $\mathrm{Sb}$ to form crystalline phases when combined with selenium such as $\mathrm{Ga}_{2} \mathrm{Se}_{3}, \mathrm{GaSe}, \mathrm{Sb}_{2} \mathrm{Se}_{3}$, etc...chalcogenide glasses free of germanium and arsenic were synthesized combining these three elements. Despite the low thermal stability can be compensated by adding iodine, one can assume that their lifetime will be decreased because of their hygroscopicity. Nonetheless, it has to be noted that components highly hygroscopic such as $\mathrm{KBr}$ or CsI are used as infrared windows when protected by adapted thin films layers. Thus, this novel family of glasses belonging to the chalcogenide glasses can open the way to further low-cost optical applications working in the infrared range. First because they are free of germanium so cheaper, secondly because they present the possibility to be doped by rare-earth because of the high amount of gallium.

\section{References and links}

1. J-L. Adam, X. Zhang, Chalcogenide glasses "Preparation, Properties and Applications $1^{\text {st }}$ Edition" Woodhead Publishing, 2013

2. Y. Lu, S. Song, Y. Gong "Ga-Sb-Se material for low-power phase change memory" Appl. Phys. Lett. 99, 243111 (2011)

3. Q. Jiao, G. Li, L. Li, "Effect of gallium environment on infrared emission in $\mathrm{Er}^{3+}$-doped galliumantimony-sulfur glasses" Sci. Rep. 7, 41168 (2017)

4. A. Yang, M. Zhang, L. Li, "Ga-Sb-S chalcogenide glasses for mid-infrared applications" J. Am. Ceram. Soc. 99[1], 12-15 (2016)

5. M. Zhu, X. Wang, C. Jiang, "Freely adjusted properties in Ge-S based chalcogenide glasses with iodine incorporation" Infrared Phys. Tech. 69, 118-122 (2015)

6. M. Rozé, L. Calvez, Y. Ledemi, "Optical and mechanical properties of glasses ans glass-ceramics based on the Ge-Ga-Se system" J. Am. Ceram. Soc. 91[11], 3566-3570 (2008)

7. J.H. Lee, W.H. Lee, J.K. Park, "Thermal properties of ternary Ge-Sb-Se chalcogenide glass for use in molded lens applications" J. Non-Crist. Sol 341, 41-46 (2016)

8. L. Calvez, P. Lucas, M. Roze, "Influence of gallium and alkali halide addition on the optical and thermo-mechanical properties of $\mathrm{GeSe}_{2}-\mathrm{Ga}_{2} \mathrm{Se}_{3}$ glass" Appl. Phys. A 89, 183-188 (2007)

9. A.W. Mao, B.G. Aitken, R.E. Youngman, "Structure of glasses in the pseudobinary system $\mathrm{Ga}(2) \mathrm{Se}(3)-\mathrm{GeSe}(2)$ : violation of chemical order and 8-N coordination rule" J. Phys. Chem. B 117 [51], 16594-16601 (2013)

10. L. Pettersson, S. Langhoff, "Theorical electric dipole moments and dissociation energies for ground states of GaH-BrH” J. Chem. Phys. 85[5], 3130-3131 (1986)

11. J. Xu, R. Yang, Q. Chen, "The effects of Te, I atoms on the properties and structure of Ge-As-Se system glasses" J. Non-Cryst. Sol 184, 302-308 (1995)

12. M. Roze, L. Calvez, M. Hubert, "Molded glass-ceramics for infrared applications" Int. J. Appl. Glass Sci. 2[2], 129-136 (2011) 
13. Y. Tver'yanovich, M. Vlcek, A. Tverjanovich, "Formation of complex structural units and structure of some chalco-halide glasses" J. Non-Cryst. Sol 333, 85-89 (2004)

14. M. Olivier, P. Nemec, G. Boudebs, "Photosensibility of pulsed laser deposited Ge-Sb-Se thin films" Opt. Mat. Express 5[4], 781-793 (2015)

15. A. Bera, K. Pal, D.V.S. Muthu, "Sharp Raman anomalies and broken adiabaticity at a pressure induced transition from band to topological insulator in $\mathrm{Sb}_{2} \mathrm{Se}_{3}$ " Phys. Rev. Lett. 110[10], 107401 (2013)

16. L. Efthimiopoulos, J. Zhang, M. Kucway, "Sb${ }_{2} \mathrm{Se}_{3}$ under pressure" Sci. Rep. 10, 1038 (2013)

17. E. Cernoskova, J. Holubova, B. Bureau "Thermoanalytical properties and structure of $\left(\mathrm{As}_{2} \mathrm{Se}_{3}\right)_{100-}$ ${ }_{x}\left(\mathrm{Sb}_{2} \mathrm{Se}_{3}\right)_{x}$ glasses by Raman and ${ }^{77} \mathrm{Se}$ MAS NMR using a multivariate curve resolution approach" J. Non-Crist. Sol. 432, 426-431 (2016)

18. M. Olivier, J.C. Tchahame, P. Nemec, "Structure nonlinear properties, and photosensibility of $\left(\mathrm{GeSe}_{2}\right)_{100-\mathrm{x}}\left(\mathrm{Sb}_{2} \mathrm{Se}_{3}\right)_{\mathrm{x}}$ glasses" Opt. Mat. Express, 4[3], 525-540 (2014)

19. P. Nemec, B. Frumarova, M. Frumar "Structure and properties of the pure and $\operatorname{Pr} 3^{+-}$doped $\mathrm{Ge}_{25} \mathrm{Ga}_{5} \mathrm{Se}_{70}$ and $\mathrm{Ge}_{30} \mathrm{Ga}_{5} \mathrm{Se}_{65}$ glasses" J. Non-Cryst. Sol 270, 137-146 (2000)

20. M. Ichikawa, T. Wakasugi, K. Kadono, "Glass formation, physico-chemical properties, and structure of glasses based on $\mathrm{Ga}_{2} \mathrm{~S}_{3}-\mathrm{GeS}_{2}-\mathrm{Sb}_{2} \mathrm{~S}_{3}$ ” J. Non-Cryst. Sol. 356, 2235-2240 (2010)

21. M.C. Drake, G.M. Rosenblatt "Raman spectroscopy of glaseous $\mathrm{GaCl}_{3}$ and $\mathrm{GaI}_{3}$ " J. Chem. Phys. 65,[10] 4067-4071 (1976)

22. M. Wihl, M. Cardona, J. Tauc, "Raman scattering in amorphous Ge and III-V compounds" J. Non-Cryst. Sol 8, 172-178 (1972)

23. K. Murase, T. Fukunaga, K. Yakushiji, "Investigation of stability of (Ge, Sn)-(S or Se $)_{4 / 2}$ cluster vibrational spectra" J. Non-Cryst. Sol 59[2], 883-886 (1983)

24. Z.G. Ivanova, E. Cernoskova, V.S. Vassilev, "Thermomechanical and structural characterization of $\mathrm{GeSe}_{2}-\mathrm{Sb}_{2} \mathrm{Se}_{3}-\mathrm{ZnSe}$ glasses" Mater. Lett. 57, 1025-1028 (2003)

25. L. Petit, N. Carlie, K. Richardson, "Effect of the substitution of S for Se on the structure of the glasses in the system $\mathrm{Ge}_{0.23} \mathrm{Sb}_{0.07} \mathrm{~S}_{0.70-x} \mathrm{Se}_{x}$ " J. Phys. Chem. Sol 66[10], 1788-1794 (2005)

26. V. Nazabal, P. Nemec, A.M. Jurdyc, "Optical waveguide based on amorphous $\mathrm{Er}^{3+}$-doped $\mathrm{Ga}-\mathrm{Ge}-$ $\mathrm{Sb}-\mathrm{S}(\mathrm{Se})$ pulsed laser deposited thin films," Thin Solid Films 518[17], 4941-4947 (2010)

\section{Acknowledgments:}

This research is supported by French Ministry of Defense (DGA Direction Générale de l'Armement) and the Brittany region grants. 